\title{
Cross-linguistic tendencies and durational contrasts in geminate consonants: an examination of Guinaang Bontok geminates
}

\author{
Katsura Aoyama \\ Department of Speech-Language \& Hearing Sciences \\ Texas Tech University Health Sciences Center \\ katsura.aoyama@ttuhsc.edu
}

Lawrence A. Reid

Department of Linguistics

University of Hawaili at Mānoa

reid@hawail.edu

\begin{abstract}
In Guinaang Bontok, there is a phonological contrast between singletons and geminates in all consonants (/p t k P b d g m n j l s w j/) (Reid 1963, 1973; Thurgood 1997). All phonological geminates except for the oral voiced stop geminates are phonetically long consonants (Reid 1963), allowing a phonological distinction which is primarily based on phonetic duration for nasals, fricatives, liquids, glides and voiceless stops. In a cross-linguistic examination of geminates (Thurgood 1993), there were more languages listed as examples for having stop and nasal geminates than for glide geminates, and it was suggested that alveolar was the cross-linguistically preferred place of articulation for geminate consonants. In this study, it was hypothesized that the cross-linguistically less common length contrasts, such as the length contrasts in glides, were phonetically less clear than the more common ones, such as contrasts between short and long stop and nasal consonants. Similarly, it was hypothesized that contrasts in the cross-linguistically common place of articulation (i.e. alveolar) is phonetically clearer than less common contrasts (e.g. velar). In order to test these hypotheses, duration measurements were conducted on single and geminate consonants in Guinaang Bontok. The average durational contrast between short and long glides was smaller than the contrast in stop and nasal consonants. The hypothesis was therefore partially supported.
\end{abstract}

\section{Introduction}

Bontok is one of the Central Cordilleran languages spoken in the municipality of Bontoc, Mountain Province in the northern Philippines (Reid 1976). This study examined single and geminate consonants in Guinaang Bontok, a dialect of the language spoken in the village of Guinaang (/gina'?an/), a community of over 2,000 residents located some 15 kilometers north of Bontoc town.

Consonant phonemes of Guinaang Bontok are $/ \mathrm{p} \mathrm{t} \mathrm{k} \mathrm{b} \mathrm{d} \mathrm{g} \mathrm{m} \mathrm{n} 1 \mathrm{~s} \mathrm{w} \mathrm{j} /$, and all of them can appear as a singleton or as geminates phonologically (Reid 1963, 1973, Thurgood 1997). ${ }^{1}$ Of these, all geminates except for the voiced stop geminates are phonetically long

\footnotetext{
$1 / \mathrm{y} /$ was used for the palatal approximant in some of the previous publications on Guinaang Bontok (e.g. Reid 1963). [.] occurs as an allophone of /1/. [1] occurs when the vowel that precedes it is /i/, regardless 
segments rather than separately articulated consonants (Reid 1963). ${ }^{2}$ It is not very common cross-linguistically that nearly all consonant phonemes can appear as long consonants as in Guinaang Bontok. First, contrasts between short and long consonants do not seem to be as common as contrasts between short and long vowels (Blevins 2004a, Ladefoged 2006). Second, not all consonants can appear as long even in languages that allow length contrasts. For instance, stops, fricatives, nasals and liquids can appear as both short and long in Finnish, but glides do not (Sulkala \& Karjalainen 1992). In Japanese, phonetically long consonants are limited to nasals and voiceless obstruents (e.g. [p t k s]) with some exceptions (Vance 1987).

Long consonants are often analyzed phonologically as a cluster of identical consonants (Lehiste 1970, Thurgood 1993), as is the case in Guinaang Bontok (Reid 1963). It has been proposed that geminate consonants are phonologically mapped onto two metrical units (Leben 1980; see also Schein \& Steriade 1986, Perlmutter 1995), and that they are phonologically both the final consonant of the preceding syllable and the initial consonant of the following syllable (Thurgood 1993). However, details of the phonological analysis of phonetically long consonants vary in different languages. ${ }^{3}$ In order to avoid lengthy discussions on phonology of each individual language, the terms SHORT/SINGLE and LONG/GEMINATE will be used interchangeably in this study. The discussions will be limited to phonological geminates (or clusters) that are phonetically long consonants in Guinaang Bontok and other languages.

The durational contrast between short and long segments may also differ depending on the segment. For vowels, it was reported that the ratio between short and long vowels was approximately 1:2 in languages such as Japanese (Han 1962), Danish, Finnish and Estonian (see Lehiste 1970 for a review). In Swedish, it was reported that long vowels were just 55\% longer than the short vowels on average (McAllister, Flege \& Piske 1999). For short and long consonants, Esposito \& Di Benedetto (1999) reported approximately a 1:2 ratio between short and long voiceless stops (/p t k/) in Italian. The ratio was much larger in Finnish; the ratio between short and long / $/$ / was 1:2.7 (Richardson 1998). The durational ratio between the short and long affricates in Polish ([tc] vs. [t:c]) ranged from 1:1.6 to 1:1.8 (Thurgood 2001), which was smaller than the ratios in stop consonants in Italian (Esposito \& Di Benedetto 1999) and Finnish (Richardson 1998). Sato (1998) studied short and long contrasts in vowels, nasals, fricatives and stops in Japanese. The durational ratios between short and long segments ranged from $1: 1.56$ to $1: 1.9$ for vowels, from $1: 2.04$ to $1: 2.83$ for nasals, from $1: 1.79$ to $1: 1.82$ for fricatives, and from 1:2.03 to 1:2.44 for stops (Sato 1998). Table 1 summarizes findings of previous studies.

The above studies seem to suggest that the durational ratio between short and long segments is comparatively small for vowels, fricatives, and affricates, ranging from 1:1.55 to $1: 2$, whereas long nasals and stops are twice or three times as long as their short counterparts. In other words, long vowels, fricatives, and affricates may not need to be twice as long as their short counterparts in order to be 'phonologically long'. Phonologically long stops and nasals, on the other hand, seem to be at least twice as long as the phonologically short stops and nasals.

of the quality of any intervening consonant, or when a laminal consonant $(/ \mathrm{t} /, / \mathrm{d} /$, or $/ \mathrm{s} /)$ immediately precedes $/ 1 /$, regardless of the quality of the preceding vowel. [1] also occurs if it is immediately followed by /i/. Word-initially after a pause, [1] occurs regardless of the quality of the following vowel. [I] occurs when $/ 1 /$ is preceded and followed by a vowel other than $/ \mathrm{i} /$, as long as there is no intervening laminal consonant (Reid 1963, 2005).

${ }^{2}$ Voiced stops only occur in inherited words in Guinaang Bontok as coda segments. In onset positions, /b/ is realized as [f], $/ \mathrm{d} /$ is realized as [ts], and $/ \mathrm{g} /$ is realized as $\left[\mathrm{k}^{\mathrm{h}}\right]$ so that while there are phonologically geminated voiced stops, phonetically long voiced stops do not occur.

${ }^{3}$ For example, phonetically long segments in Japanese are analyzed as 'mora' phonemes followed by the initial consonant of the following syllable, not as geminates (Vance 1987). 
Table 1 Summary of previous studies.

\begin{tabular}{llll}
\hline Segment(s) & Language & Averaged ratio short: long & \multicolumn{1}{c}{ Source } \\
\hline vowels & Japanese & $1: 2-1: 3$ & Han (1962) \\
vowels & Japanese & $1: 1.56-1: 1.9$ & Sato (1998) \\
vowels & Swedish & $1: 1.55$ & McAllister, Flege \& Piske (1999) \\
stops & Italian & $1: 2$ (approximately) & Esposito \& Di Benedetto (1999) \\
stops & Japanese & $1: 2.03-1: 2.44$ & Sato (1998) \\
/t/ & Finnish & $1: 2.7$ & Richardson (1998) \\
fricatives & Japanese & $1: 1.79-1: 1.82$ & Sato (1998) \\
$/ \mathbf{t}$ c/ & Polish & $1: 1.6-1: 1.8$ & Thurgood (2001) \\
nasals & Japanese & $1: 2.04-1: 2.83$ & Sato (1998) \\
/n/ & Japanese & $1: 2.51$ & Aoyama (2001) \\
/n/ & Finnish & $1: 2.88$ & Aoyama (2001) \\
\hline
\end{tabular}

Thurgood (1993) examined phonemic inventories of different languages and proposed cross-linguistic preferences for geminate consonants. For instance, he proposed that the most favored phonological environment for geminates is intervocalic between a short stressed vowel and preceding another short vowel. It was also proposed that alveolar is the most preferred place of articulation for geminates, followed by bilabial then velar, regardless of manners of articulation.

However, Blevins (2004a, b, c) suggests that there are no such absolute implicational relationships regarding geminates cross-linguistically and that geminate inventories reflect how each instance evolved through historical sound changes rather than more general crosslinguistic tendencies. She predicts that there may be some cross-linguistic tendencies in geminate inventory, such as absence of sibilant geminates, but suggests that such tendencies evolve because of phonetically-motivated sound change (Blevins 2004a, b, c). For example, she suggests that sibilant geminates $/ \mathrm{si} /$ and $/ \mathrm{z}: /$ are more likely to be missing than stops in a geminate inventory, because inherent durations of sibilants are longer than those of other segments and therefore the length contrast in these segments is more susceptible for neutralization (Blevins 2004b, c).

This study investigates whether there is a phonetic basis for cross-linguistically less common length contrasts, such as absence of glide geminates. In the Stanford phonology archive (Crothers, Lorentz, Sherman \& Vihman 1979), there are only a handful of languages in which geminate glides occur, but there are many languages in which geminate stops and nasals occur. ${ }^{4}$ Blevins (2004a) reports that glide geminates were not found in Taba, and that they were the only consonants that cannot be geminated in Meidob Nubian. In addition, languages in which geminate glides are found (e.g. Dobel, Piro, Chuvash, Marshallese) also allow other geminate consonants (for Dobel, see Blevins 2004a; for Piro and Chuvash, see Blevins 2004c; for Marshallese, see Bender 1968). Based on these observations, we hypothesize that this may be another instance of a common gap in geminate inventories, and that this gap may be phonetically motivated. We hypothesize that phonetic contrasts between short and long consonants are smaller in glides, which appears to be cross-linguistically less common than contrasts such as nasal and oral stop geminates. This hypothesis concerns cross-linguistic tendencies, and does not imply any absolute universals, or implicational relationships in geminates.

\footnotetext{
${ }^{4}$ It was reported that at least one glide phoneme can be geminated in the following languages: Zuni, Chuvash, Kurukh, Mahas-Fiyadikka, Maasai, Hindi-Urdu, Hungarian, Tigre, Egyptian and Moroccan Arabic, Maltese, Songhai (Crothers, et al., 1979).
} 
In order to examine geminates of different segments, an experiment was conducted in Guinaang Bontok in which / $\mathrm{pt} \mathrm{k} \mathrm{m} \mathrm{n} \mathrm{n} 1 \mathrm{~s} \mathrm{w} \mathrm{j} /$ can occur as geminates that are phonetically one long consonant. The clarity of phonetic contrast between single and geminate consonants was examined in two ways: (1) mean absolute durations of single and geminate consonants, and (2) durational ratios between singletons and geminates.

\section{Method}

\subsection{Materials}

A list of ninety-six Guinaang Bontok words and pseudo-words was prepared. The list consisted of pairs or triplets of words that contrasted by the length of the word-medial consonant. ${ }^{5}$ The medial consonants that contrasted in length were voiceless stops ([p t k P], 27 words), nasals ([m n $]$ ], 25 words), a fricative ([s], 7 words), liquids ([1] and [I], 16 words), and glides ([w j], 21 words). Of these, seventy-eight words were existing words in Guinaang Bontok. Eighteen pseudo-words were used in order to create pairs or triplets contrasting by the length of the medial consonants. The pseudo-words were created on the basis of an existing word, and they were all phonotactically well-formed in Guinaang Bontok. The participants did not seem to have difficulty reading the pseudo-words.

The words and pseudo-words were presented in a frame sentence (see appendix). When the initial consonant of the target word was a stop 6 or an affricate, (a) Apedna kinwániyen (the target word ) 'He just said (the target word )' was used. When the initial consonant of the target word was a liquid, a nasal or a fricative, (b) Nan kinwánina ket (the target word) 'What he said was the target word' was used. Alternate frame sentences were used when the target word was a name or a pseudo-name. In those cases, (c) Si (the target word) nan inayákhana 'The target word is the one he called' was used.

\subsection{Data collection and data analysis}

The participants were ten native speakers of Guinaang Bontok (five males, five females). They were all residents of the Guinaang village in Mountain Province in the northern Philippines. The participants' ages varied from 14 years to their $50 \mathrm{~s} .{ }^{7}$ Equal numbers of male and female participants were included to examine whether gender would influence the contrast in any way. They participated in groups which consisted of two to four participants each. The data collection was conducted in a participant's house in the village, using a SONY digital tape recorder with a microphone.

The words and frame sentences were written on a notebook using the local orthography, ${ }^{8}$ which was placed on the floor among the participants. The frame sentences were written on the notebook, and the target word was presented one at a time by replacing a small sticky note with a target word on it. The words were also presented orally by the second author who speaks Guinaang Bontok fluently. The words were pseudo-randomized so that the words in the pairs or triplets did not appear one after the other. The participants were asked to say each

\footnotetext{
${ }^{5}$ Note that they may not MINIMALLY contrast by the length of the medial consonant. The appendix lists the words that were analyzed in this study.

${ }^{6}$ A glottal stop precedes all vowels word-initially in Guinaang Bontok (Reid 1963).

${ }^{7}$ The older participants did not know their exact age or that of others.

${ }^{8}$ In the local orthography, $r$ is used for the [.] allophone of /l/. ch is used for the [ts] prevocalic allophone of $/ \mathrm{d} /$, and $k h$ is used for the $\left[\mathrm{k}^{\mathrm{h}}\right]$ prevocalic allophone of $/ \mathrm{g} /$. Glottal stop is represented by a hyphen when it occurs as the second member of a consonant cluster. Glottal stop does not occur as the first member of a consonant cluster.
} 
word in isolation first, and then to repeat the word in the frame sentence twice. Thus, three tokens (one in isolation and two in the frame sentence) were collected for each target word from each participant.

Of the ninety-six words, sixty-six were selected and acoustically analyzed (see appendix). Words that included glottal stops were not included in the analysis because it was difficult to determine the onset and offset of the glottal stop. An effort was made to include three pairs of singleton-geminates for each consonant in the analysis. Preferences were given to words that (1) consisted of two syllables, (2) had stress on the first syllable, and (3) were produced in the frame sentence (a). There were exceptions for each criterion. Thirty-three words included single consonants and the other thirty-three words included geminate consonants. The target single or geminate consonants always appeared intervocalically.

The recordings were digitized at $22.05 \mathrm{~Hz}$, and the data were analyzed acoustically using the program PitchWorks by Scicon R\&D. Wideband spectrograms were produced for each target word and the durations of single and geminate consonants were measured in milliseconds. The consonant duration was measured using the waveform and wideband spectrograms with reference to the acoustic characteristics of consonants (Kent \& Read 1992). For oral stop consonants, the duration was measured from the beginning of the stop closure to the onset of voicing (i.e. voice-onset time (VOT) was included). The duration of the fricative noise and nasal murmur were measured for $/ \mathrm{s} /$ and nasal consonants, respectively. The durations of liquids and glides were more difficult to measure because of their transient nature (Kent \& Read 1992, Maltínez-Celdrán 2004). The durations of [w j 1 I ] were therefore measured as the duration between the end of the steady state of the preceding vowel and the beginning of the steady state of the following vowel. ${ }^{9}$

A total of 1,945 tokens ( 66 words $\times 3$ repetitions $\times 10$ participants, 35 missing tokens) were analyzed. The reasons for the missing data included missed repetitions (19 tokens), overlapping noise (9 tokens), soft voice ( 4 tokens), and repetitions of a different word (3 tokens).

\section{Results}

\subsection{Overall results}

Table 2 shows the overall average duration of each consonant (as singleton and geminate). The duration values of the tokens produced in isolation and in the frame sentences were averaged because the values of the productions in isolation and in the frame sentences were highly correlated in all 10 participants $(r>.70$ to $r>.94, p<0.01)$, and because it has been reported that single and geminate consonants are clearly differentiated both in isolation and at slower and faster speaking rates (Pickett, Blumstein \& Burton 1999). Then the duration values for each single and geminate consonant ( 9 tokens) were averaged over three test words for each participant. For instance, the average duration of singleton [p] was based on three repetitions each of Ápo 'grandfather', ípit 'to squeeze', and kópot (a pseudo-word).

The average durations for each consonant from each participant were statistically analyzed using an analysis of variance (ANOVA). Phoneme (11 levels) and Single/Geminate contrast (2 levels) were within-subject variables and Participant was a random variable. The effect of Single/Geminate contrast was significant $(F(1,189)=981.45, p<.001)$, and post-hoc tests

\footnotetext{
${ }^{9}$ It is possible that the measurement methods affected the durations and ratios between singletons and geminates, because parts of the vowels are included in durations of liquids and glides, but not in the duration of the other segments. However, we do not believe that this measurement method contributed to differences between approximants (liquids and glides) and other consonants, because only the $[\mathrm{j}]-[\mathrm{j}:]$ contrast, not all of the liquids and glides, differed from other contrasts.
} 
Table 2 The average duration for each consonant and their durational ratios.

\begin{tabular}{lllcc}
\hline & Average in ms (SD) & & Average in ms (SD) & Ratio single: geminate \\
\hline$[\mathrm{p}]$ & $83(22)$ & {$[\mathrm{p:}]$} & $147(37)$ & 1.87 \\
{$[\mathrm{t}]$} & $79(20)$ & {$[\mathrm{t}]$} & $150(43)$ & 1.91 \\
{$[\mathrm{k}]$} & $73(25)$ & {$[\mathrm{k:}]$} & $137(40)$ & 1.90 \\
{$[\mathrm{~s}]$} & $99(21)$ & {$[\mathrm{si}]$} & $151(40)$ & 1.56 \\
{$[\mathrm{~m}]$} & $74(16)$ & {$[\mathrm{m:}]$} & $146(26)$ & 1.99 \\
{$[\mathrm{n}]$} & $67(13)$ & {$[\mathrm{n:}]$} & $144(29)$ & 2.15 \\
{$[\mathrm{n}]$} & $77(18)$ & {$[\mathrm{n:}]$} & $131(26)$ & 1.72 \\
{$[1]$} & $72(14)$ & {$[\mathrm{li}]$} & $145(29)$ & 2.00 \\
{$[\mathrm{I}]$} & $82(16)$ & {$[\mathrm{ri}]$} & $127(23)$ & 1.56 \\
{$[\mathrm{w}]$} & $75(21)$ & {$[\mathrm{w:}]$} & $128(34)$ & 1.69 \\
{$[\mathrm{j}]$} & $87(17)$ & {$[\mathrm{j:}]$} & $120(25)$ & 1.39 \\
\hline
\end{tabular}

Note: Each average value was based on measurements of 90 tokens (3 words $x 3$ repetitions $x 10$ speakers) for most cases. Some of the mean values were based on fewer than 90 tokens due to missing data. Standard deviations are in parentheses.

showed that Single/Geminate contrast was significant in all 11 consonant pairs (t-ratio $=5.19$ to $12.07, p<.001)$. The effect of Participant was significant $(F(8,189)=27.13, p<.001)$, indicating that duration values differed among the participants. ${ }^{10}$ The effect of Phoneme was also significant $(F(10,189)=5.00, p<.001)$. This is due to varying average durations for singletons and geminates for each consonant. The durational contrast between singletons and geminates was the largest for [n]-[n:] (mean $67 \mathrm{vs}$. $144 \mathrm{~ms}$, ratio 1:2.15), and the smallest for $[\mathrm{j}]-[\mathrm{j}:]$ (mean $87 \mathrm{vs} .120 \mathrm{~ms}$, ratio 1:1.39). The ratios between singleton and geminates ranged from 1.87 to 2.00 for $[\mathrm{p}]-[\mathrm{pr}],[\mathrm{k}]-[\mathrm{ks}],[\mathrm{t}]-[\mathrm{t}:],[\mathrm{m}]-[\mathrm{m:}]$, and $[1]-[\mathrm{l}]]$ (in the order from the smaller ratio to the larger ratio). They ranged from 1.56 to 1.72 for [s] $-[\mathrm{si}],[\mathrm{I}]-[\mathrm{s}]$, $[\mathrm{w}]-[\mathrm{w}:]$, and $[\mathrm{y}]-[\mathrm{y}:]$ (from the smaller ratio to the larger ratio; see table 2). For illustration, figure 1 shows the distribution of duration values for all consonants, rank ordered by the smallest ratio $([\mathrm{j}]-[\mathrm{j}]])$ to the largest ratio $([\mathrm{n}]-[\mathrm{n}:])$. Each box shows the values between the 25 th and 75 th percentiles, and the line in the box indicates the median value. It can be seen that the durational values were more clearly differentiated for some contrasts, such as [n]-[n: $]$, than for others, such as $[\mathrm{j}]-[\mathrm{j}:]$.

The average ratios for each consonant from each participant were also analyzed using an ANOVA. Phoneme (11 levels) was a within-subject variable, and Participant was a random variable. The effect of Phoneme was significant $(F(10,90)=9.56, p<.001)$. The effect of Participant was also significant $(F(8,90)=7.19, p<.001)$. Tukey's post-hoc tests on the effect of Phoneme showed that the ratios for $[\mathrm{p}]-[\mathrm{pr}],[\mathrm{t}]-[\mathrm{t}:],[\mathrm{k}]-[\mathrm{k}:],[1]-[\mathrm{l}:],[\mathrm{m}]-[\mathrm{m:}]$, and $[\mathrm{n}]-[\mathrm{n}:]$ were significantly larger than those for $[\mathrm{j}]-[\mathrm{j}] \mathrm{j}(p<0.01)$. It also showed that the ratios for $[1]-[\mathrm{l}],[\mathrm{t}]-[\mathrm{tr}],[\mathrm{m}]-[\mathrm{mi}]$, and $[\mathrm{n}]-[\mathrm{n}:]$ were larger than those for $[\mathrm{s}]-[\mathrm{st}]$ and $[\mathrm{r}]-[\mathrm{ri}]$, and the ratio for [n]-[n:] was larger than those for [w]-[w:] and [n]-[y:] $(p<0.01)$. Other post-hoc pair-wise comparisons were not statistically significant.

In order to test the hypothesis regarding the place of articulation, closer attention was paid for $[\mathrm{p}]-[\mathrm{p}:],[\mathrm{t}]-[\mathrm{t}:]$, and $[\mathrm{k}]-[\mathrm{ki}]$ and $[\mathrm{m}]-[\mathrm{mi}],[\mathrm{n}]-[\mathrm{n:}]$, and $[\mathrm{n}]-[\mathrm{p}:]$. Tukey's post-hoc pair-wise comparisons showed that the ratios for [n]-[n:] were significantly larger than those for $[\mathrm{\eta}]-[\mathrm{\eta}:](p<0.01)$, indicating a clearer distinction for $[\mathrm{n}]-[\mathrm{n}:]$ than for $[\mathrm{n}]-[\mathrm{y}:]$. Figure 2 shows the distribution of duration values for $[\mathrm{n}]-[\mathrm{n}:]$ and $[\mathrm{\eta}]-[\mathrm{y}:]$. Other pair-wise comparisons

${ }^{10}$ The effect of Gender was also examined. The effect was not statistically significant $(F(1,189)=.089$, $p>0.1)$, and did not interact with any other factors. It was non-significant in all other analyses in this article, and will not be reported or discussed further. 


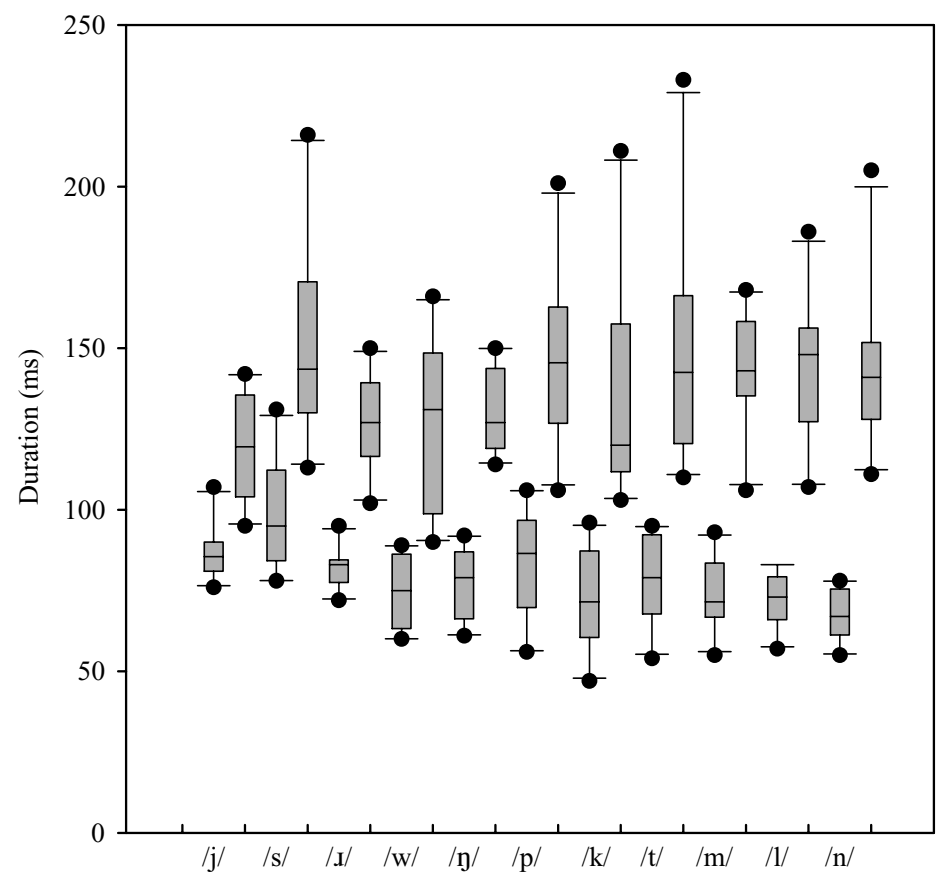

Figure 1 Distribution of duration values for all consonants, rank ordered by the smallest ratio $([\mathbf{j}]-[\mathbf{j}]])$ to the largest ratio $([n]-[n:])$.

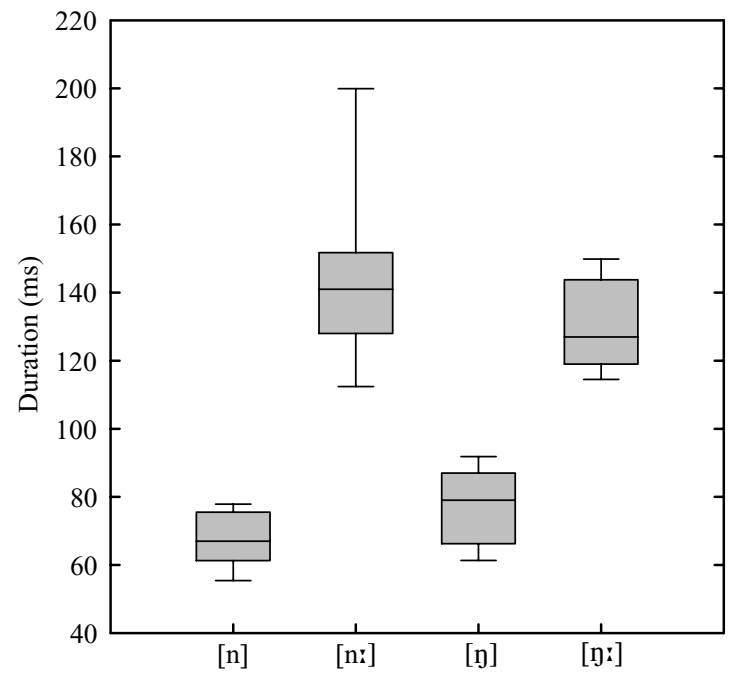

Figure 2 Distribution of duration values for [n]-[n:] and [n]-[n:].

were not statistically significant, indicating no significant differences between $[\mathrm{m}]-[\mathrm{m}:]$ and $[\mathrm{\eta}]-[\mathrm{p}:],[\mathrm{m}]-[\mathrm{m:}]$ and $[\mathrm{n}]-[\mathrm{n}:]$, nor were there statistically significant differences among oral stop consonants. 


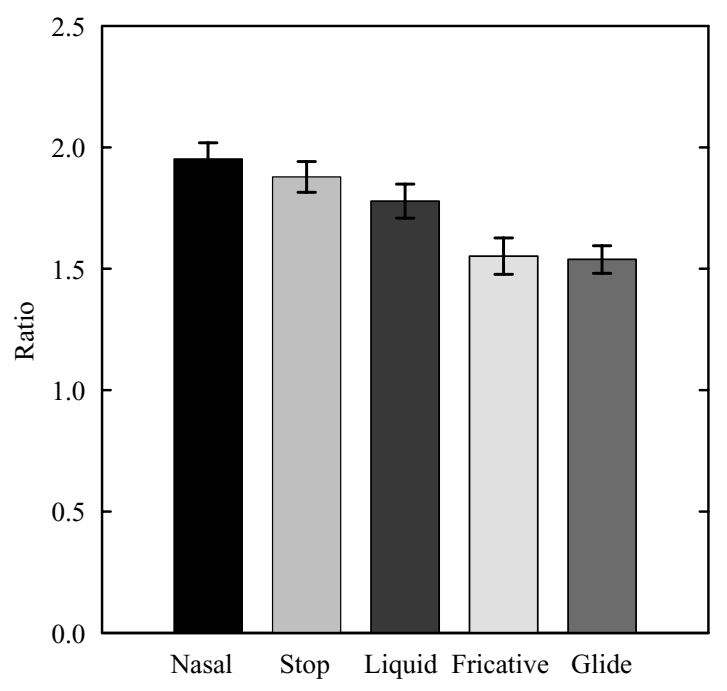

Figure 3 The average ratios for nasals, stops, liquids, fricatives and glides, rank ordered by the largest ratio (nasals) to the smallest ratio (glides). Error bars stand for standard errors.

\subsection{Manner of articulation}

In order to test the hypothesis regarding the manners of articulation, the durational ratios were examined by categories. The average ratios for each consonant for each participant were coded as stops $([\mathrm{p}]-[\mathrm{pr}],[\mathrm{t}]-[\mathrm{t}:],[\mathrm{k}]-[\mathrm{kz}])$, fricative $([\mathrm{s}]-[\mathrm{s}:])$, nasals $([\mathrm{m}]-[\mathrm{m}:],[\mathrm{n}]-[\mathrm{n}:],[\mathrm{n}]-[\mathrm{n}:])$, liquids ([1]-[li], [.] $-[\mathrm{x}])$, and glides $([\mathrm{w}]-[\mathrm{w:}],[\mathrm{j}]-[\mathrm{j}:])$ and analyzed in a one-way ANOVA. This analysis showed that the effect of Category was significant $(F(4,109)=6.81, p<.001)$. Tukey's post-hoc pair-wise comparisons showed that the ratios for nasals and stops were significantly larger than those for glides $(p<.01)$. In addition, the ratios for nasals were also significantly larger than those for fricatives $(p<.01)$. Other post-hoc pair-wise comparisons were not statistically significant.

Figure 3 shows the average ratios for the five categories. The average ratio was the largest for nasals (1.95), and the smallest for glides (1.54). The average ratio for stops was the second largest (1.88) and that for liquids was the third largest (1.79). The average ratio for fricatives was the second smallest (1.55). Note that there is only one fricative in Guinaang Bontok $(/ \mathrm{s} /)$, and the ratio for fricatives is based on fewer data points.

\section{Discussion}

The experimental data from Guinaang Bontok suggest that all geminate consonants were clearly differentiated from single consonants in duration. Nonetheless, the phonologically binary length contrast was phonetically realized differently for different consonants. For instance, durational contrasts were the largest for $[\mathrm{n}]-[\mathrm{n}:]$, and the smallest for $[\mathrm{j}]-[\mathrm{j}:]$ (see table 2 and figure 1). The contrast in duration for [j]-[ji] was significantly smaller than the contrasts for $[\mathrm{p}]-[\mathrm{pr}],[\mathrm{t}]-[\mathrm{t}:],[\mathrm{k}]-[\mathrm{ki}],[1]-[\mathrm{l}],[\mathrm{m}]-[\mathrm{mi}]$, and $[\mathrm{n}]-[\mathrm{n}:]$. The contrast in duration for $[\mathrm{n}]-[\mathrm{ni}]$ was significantly larger than the contrasts for $[\mathrm{s}]-[\mathrm{si}],[\mathrm{I}]-[\mathrm{Ir}],[\mathrm{w}]-[\mathrm{W}:]$, and $[\mathrm{y}]-[\mathrm{\eta}:]$. In addition, the average absolute duration of phonologically 'short' and 'long' consonants varied considerably. The average duration of phonologically 'short' consonants ranged from $67 \mathrm{~ms}([\mathrm{n}])$ to $99 \mathrm{~ms}([\mathrm{~s}])$, and the average duration of phonologically 'long' consonants ranged from $120 \mathrm{~ms}([\mathrm{j}:])$ to $151 \mathrm{~ms}([\mathrm{~s}:])$. In other words, the absolute duration of phonologically 'short' or 'long' consonant depends on the kind of consonant; $110 \mathrm{~ms}$ can be phonologically 'short' for the $[\mathrm{s}]-[\mathrm{si}]$ contrast but 'long' for the $[\mathrm{j}]-[\mathrm{j}:]$ contrast. 
The results of this study suggest that the hypothesis regarding the manner of articulation and cross-linguistic preference of geminate consonants is partially supported. The ratios for glides $([\mathrm{w}]-[\mathrm{w}:]$ and $[\mathrm{j}]-[\mathrm{j}] \mathrm{j})$ were significantly smaller than the ratios for nasals and stops. The difference was not found, however, among liquids, stops, and nasals. It may be that glide consonants cannot be lengthened as other consonants, because they are 'transitions' to a following vowel (Edwards 2003:35). As a consequence, the contrast between short and long glides in languages may be difficult to maintain.

The contrast between [1] and [1:] was much larger than the contrasts in other liquid and glide geminates. In fact, the contrast between [1] and [1:] was the second largest of all consonants (mean $72 \mathrm{vs} .145 \mathrm{~ms}$, ratio 1:2.00). This may be due to the fact that the tongue tip moves more rapidly compared to other articulators (Lehiste 1970), and the duration may be more easily controlled for alveolar consonants (see Lehiste 1970, Maddieson 1997). Other alveolar contrasts ${ }^{11}$ in this study, $[\mathrm{n}]-[\mathrm{n}:]$ and $[\mathrm{t}]-[\mathrm{t}:]$ were also among those that had the largest durational contrasts as well (see figure 1).

However, no consistent patterns were found in durations of geminate consonants regarding the place of articulation. Alveolar/dental nasals are the most common places of articulation for nasal geminates (Thurgood 1993) and for phoneme inventories in general (Maddieson 1984), followed by bilabial then velar. In this study, no significant differences were found in the durational ratios for oral stops (/p t k/). Among the nasal stops, no significant differences were found between bilabial and alveolar nasals, nor bilabial and velar nasals. The only difference that reached statistical significance was between alveolar and velar nasals; the ratios for $[\mathrm{n}]-[\mathrm{n}:]$ was significantly larger than that for $[\mathrm{n}]-[\mathrm{n}:]$ (see figure 2).

The contrast in $/ \mathrm{s} /$ seemed to differ from contrasts in other consonants. The contrast between [s] and [s:] was rather small on average ( $99 \mathrm{~ms}$ vs. $151 \mathrm{~ms}$, ratio 1:1.56, see table 2). Sato (1998) also reported a smaller durational ratio between short and long fricatives (103 ms vs. $185 \mathrm{~ms}$, ratio $1: 1.80)$ compared to short and long stops and nasals. Fricatives are intrinsically longer than stops, nasals, and liquids (Lehiste 1970, Edwards 2003), therefore the phonologically short fricatives are inevitably longer than the other short segments. The contrast seems to be well-maintained because the geminate fricatives were also long (mean $151 \mathrm{~ms}$ ). Contrasts in fricatives need to be examined further in a different language, because $/ \mathrm{s} /-/ \mathrm{s} /$ is the only singleton-geminate contrast in fricatives that is primarily distinguished by duration in Guinaang Bontok (Reid 1963, 1973, Thurgood 1997). ${ }^{12}$

The phonetic contrasts between short and long consonants in Guinaang Bontok appeared to be somewhat smaller compared to those in other languages. ${ }^{13}$ For stop consonants in Italian, Esposito \& Di Benedetto (1999) reported duration of single [ $\mathrm{pt}$ k] to be approximately $100 \mathrm{~ms}$, and geminate [p: t: k:] to be approximately $200 \mathrm{~ms}$. In Japanese, the average duration of single stop consonants was $70 \mathrm{~ms}$ and the average duration of geminate stop consonants was $157 \mathrm{~ms}$ in Sato (1998). Similar values (79 ms vs. $198 \mathrm{~ms}$ ) to Sato (1998) were reported for Japanese stop consonants in Han (1994). In Richardson (1998), much larger values, 118 ms vs. 319 ms on the average, were found in adult production data in Finnish. It is probably because adult participants in Richardson (1998) were instructed to produce the target words in a manner in which they would ask children to imitate. In all the above studies, the durational ratios between single and geminate stops in Italian, Finnish and Japanese ranged from 1:2 (Italian

${ }^{11}$ All coronal segments in Guinaang Bontok are laminal with either alveolar or postalveolar points of articulation.

${ }^{12}$ Phonetically, [f] occurs in Guinaang Bontok. It occurs as the prevocalic allophone of $/ \mathrm{b} /$, so no length contrast between $[\mathrm{f}]$ and $[\mathrm{f}:]$ is possible.

${ }^{13}$ It has been pointed out that comparison across studies is difficult because of differences in measurements, and we do not claim that these values are directly comparable. For Esposito \& Di Benedetto (1999), the values can only be read from figure 7. Han (1994) and Sato (1998) reported the average duration of each test word, and the average duration of each consonant was calculated by the authors. Voice onset time (VOT) was included as a part of the consonant in both cases. 
- Esposito \& Di Benedetto 1999) to 1:2.7 (Finnish - Richardson 1998), and were larger than the ratio between short and long stops in Guinaang Bontok (1:1.86).

The durational ratio in nasals in Guinaang Bontok was also smaller than those in other languages. In Guinaang Bontok, the average duration of single nasals was $73 \mathrm{~ms}$, and the average duration of geminate nasals was $140 \mathrm{~ms}$ (ratio 1:1.92). In Japanese, the average duration of short nasals was $50 \mathrm{~ms}$, and the average duration of long nasals was $125 \mathrm{~ms}$ in Sato (1998). In Aoyama (2001), the average duration of [n] was $68 \mathrm{~ms}$ and the average duration of [n:] was $172 \mathrm{~ms}$ in Japanese (ratio 1:2.51). In Guinaang Bontok, the average duration of [n] was $67 \mathrm{~ms}$, and that of [n:] was $144 \mathrm{~ms}$ (ratio 1:2.15). The Finnish contrast seems to be the largest for nasal consonants as well as for stop consonants; the average duration of [n] was $62 \mathrm{~ms}$ and the average duration of [n:] was $178 \mathrm{~ms}$ (ratio 1:2.88) (Aoyama 2001). The ratios between short and long nasal consonants were over 1:2.5 in both Finnish (Aoyama 2001) and Japanese (Sato 1998, Aoyama 2001). The durational ratio for [n]-[n:] in Guinaang Bontok $(1: 2.15)$ was smaller than similar contrasts in Finnish and Japanese, although the contrast in nasals was larger than those in consonants of other manners of articulation in Guinaang Bontok.

In summary, it is possible to associate cross-linguistically less common length contrasts, such as glide geminates, with aspects of the phonetic realizations of these segment types. The data from Guinaang Bontok suggest that a phonologically binary length contrast can be phonetically realized differently for different consonants. The acoustic analyses of single and geminate consonants in Guinaang Bontok suggest that the phonological length contrast is phonetically clearer in stops and nasals than in glides. If this is the case across languages phonetically, neutralization of length contrasts for glides is expected to be more common cross-linguistically than length neutralization for oral and nasal stops, similar to Blevins's (2004b) suggestion for sibilants. These findings are consistent with the view that length contrasts which are less common cross-linguistically may reflect common phonetically-based instances of sound change (Blevins 2004a, b), and observed tendencies in geminate inventories (Thurgood 1993) may be phonetically grounded.

\section{Acknowledgements}

The authors sincerely thank all the participants and the Catay family of Guinaang village in the Philippines. We also thank Graham Thurgood and Elzbieta Thurgood for their discussions, and John Esling, Henning Reetz and an anonymous reviewer for comments on a previous version. Henning Reetz was particularly helpful and assisted us to improve statistical analyses of the data. Previous versions of this article were presented at California State University, Chico (February 2003), Austronesian Formal Linguistics Association (March 2003) and the Acoustical Society of America (November 2003). We thank Sarai Granados, Lacey Decker, Brittany Dendle and Shayna Peabody for their assistance. Financial support was provided by the Arts and Sciences Advisory Council of the University of Hawai' $i$ at Mānoa.

\section{Appendix: The list of words and frame sentences}

See footnote 8 for explanations of the local orthographic system.

\section{Frame sentences}

(a) Apedna kinwániyen (the target word).

(b) Nan kinwánina ket (the target word).

(c) Si (the target word) nan inayákhana.

'He just said ___.'

'What he said was

'___ is the one he called.' 


\section{The word list}

\begin{tabular}{|c|c|c|c|}
\hline & Target word & Gloss & $\begin{array}{l}\text { Frame } \\
\text { sentence used }\end{array}$ \\
\hline \multicolumn{4}{|l|}{ Stop } \\
\hline \multirow[t]{6}{*}{ [p] } & ápo & grandfather & c \\
\hline & appo & a pseudo-word & c \\
\hline & ipit & squeeze & a \\
\hline & ippit & a pseudo-word & a \\
\hline & kópot & a pseudo-word & a \\
\hline & koppot & a kind of mushroom & a \\
\hline \multirow[t]{6}{*}[\mathrm{t}]{} & aníto & the spirit of an ancestor & a \\
\hline & an-anitto & act as though possessed by a spirit & a \\
\hline & kotó & head lice & a \\
\hline & kotkotto & a kind of plant & a \\
\hline & Páta & a made-up name & c \\
\hline & patta & a woman's waist band & a \\
\hline \multirow[t]{6}{*}[\mathrm{k}]{} & kokó & the nail of one's finger or toe & a \\
\hline & kokko & a pseudo-word & a \\
\hline & kákak & a kind of bird & a \\
\hline & kakkak & a clacking sound & a \\
\hline & ókip & pack & a \\
\hline & okkip & a pseudo-word & a \\
\hline \multicolumn{4}{|c|}{ Fricative } \\
\hline \multirow[t]{6}{*}[\mathrm{s}]{} & Lising & a made-up name & $c$ \\
\hline & lissing & a kind of beetle & $b$ \\
\hline & isónga & that's why & a \\
\hline & Isso & a female name & c \\
\hline & esék & seed kept for planting & a \\
\hline & es-essek & pretend to plant & a \\
\hline \multicolumn{4}{|l|}{ Nasal } \\
\hline \multirow[t]{6}{*}[\mathrm{m}]{} & amó & be tame & a \\
\hline & ammo & know & a \\
\hline & amá & father & $c$ \\
\hline & amma & do something gently & a \\
\hline & óma & cut down grass & a \\
\hline & Omma & a made-up name & c \\
\hline \multirow[t]{6}{*}[\mathrm{n}]{} & ay anáy & why & a \\
\hline & annay & expression of pleasure & a \\
\hline & anák & child & a \\
\hline & an-annak & children & a \\
\hline & iná & mother & a \\
\hline & inna & a pseudo-word & a \\
\hline \multirow[t]{6}{*}[\mathrm{n}]{} & tongá & a pseudo-word & a \\
\hline & tongnga & an ear of corn & a \\
\hline & engér & nose & a \\
\hline & engngerán & a person with a high-bridged nose & a \\
\hline & langés & flat-nosed & b \\
\hline & Langnges & a made-up name & c \\
\hline
\end{tabular}




\begin{tabular}{|c|c|c|c|}
\hline & Target word & Gloss & $\begin{array}{l}\text { Frame } \\
\text { sentence used }\end{array}$ \\
\hline \multicolumn{4}{|c|}{ Liquid } \\
\hline \multirow[t]{6}{*}[1]{} & fáli & be included & $b$ \\
\hline & falli & a kind of plant & $b$ \\
\hline & îlang & a portion of fresh meat & a \\
\hline & Illang & name of a place & a \\
\hline & alíng & a pseudo-word & a \\
\hline & alling & earring & a \\
\hline \multirow[t]{6}{*}[\mathrm{I}]{} & árang & rice granary & a \\
\hline & arrang & bagasse & a \\
\hline & nafáro & widow & $b$ \\
\hline & fafarro & unmarried men & $b$ \\
\hline & arók & urge & a \\
\hline & arrok & a simple-minded person & a \\
\hline \multicolumn{4}{|l|}{ Glide } \\
\hline \multirow[t]{6}{*}[\mathrm{w}]{} & kháwa & center & a \\
\hline & khawwa & middle finger & a \\
\hline & sowák & remove the outer skin & $b$ \\
\hline & sowwak & a kind of grass & $b$ \\
\hline & fáwi & a small house & $b$ \\
\hline & fawwi & a pseudo-word & $b$ \\
\hline \multirow[t]{6}{*}[\mathbf{j}]{} & cháya & sky & a \\
\hline & Chayya & a person's name & a \\
\hline & cháyon & swing & a \\
\hline & chayyong & a kind of rice & a \\
\hline & káyang & play with water & a \\
\hline & kayyang & a kind of wine jar & a \\
\hline
\end{tabular}

\section{References}

Aoyama, K. (2001). A Psycholinguistic Perspective on Finnish and Japanese Prosody: Perception, Production and Child Acquisition of Consonantal Quantity Distinctions. Boston, MA: Kluwer Academic Publishers.

BENDER, B. (1968). Marshallese phonology. Oceanic Linguistics 7(2), 16-35.

Blevins, J. (2004a). Evolutionary Phonology. Cambridge: Cambridge University Press.

BLEVINS, J. (2004b). Klamath sibilant degemination: Implications for a recent sound change. International Journal of American Linguistics 70, 279-289.

BLEVINS, J. (2004c). Geminate inventories: explaining recurrent sound patterns. Paper presented at Max Planck Institute for Evolutionary Anthropology, March 26, 2004.

Crothers, J. H., Lorentz, J. P., Sherman, D. \& Vihman, M. M. (1979). Handbook of Phonological Data from a Sample of the World's Languages: A Report of the Stanford Phonology Archive, vol. 2: Indexes. Stanford, CA: Department of Linguistics, Stanford University.

Edwards, H. T. (2003). Applied Phonetics: The Sounds of American English (3rd edn.). Clifton Park, NY: Delmar Learning.

Esposito, A. \& Di BenedetTo, M. G. (1999). Acoustical and perceptual study of gemination in Italian stops. Journal of the Acoustical Society of America 106, 2051-2062.

HAN, M. S. (1962). The feature of duration in Japanese. Onsei no Kenkyuu [Study of sounds] 10, 65-80.

HAN, M. S. (1994). Acoustic manifestations of mora timing in Japanese. Journal of the Acoustical Society of America 96, 73-82. 
Kent, R. D. \& READ, C. (1992). The Acoustic Analysis of Speech. San Diego, CA: Singular Publisher Group.

LAdEFoged, P. (2006). A Course in Phonetics (5th edn.). Boston, MA: Thomson.

LEBEN, W. (1980). A metrical analysis of length. Linguistic Inquiry 11, 497-509.

LEHISTE, I. (1970). Suprasegmentals. Cambridge, MA: MIT Press.

MADDIESON, I. (1984). Patterns of Sounds. Cambridge: Cambridge University Press.

Maddieson, I. (1997). Phonetic universals. In Hardcastle, W. J. \& Laver, J. (eds.), The Handbook of Phonetic Sciences, 619-639. Malden, MA: Blackwell.

MARTínEZ-CeldRÁN, E. (2004). Problems in the classification of approximants. Journal of the International Phonetic Association 34, 201-210.

McAllister, R., Flege, J. E. \& Piske, T. (1999). The acquisition of Swedish long vs. short vowel contrasts by native speakers of English and Spanish. In Ohala, J., Hasegawa, Y., Ohala, M., Dranville, D. \& Bailey, A. (eds.), Proceedings of the XIVth International Congress of Phonetic Sciences, 751-754. Berkeley, CA: Department of Linguistics, University of California at Berkeley.

Perlmutter, D. (1995). Phonological quantity and multiple association. In Goldsmith, J. A. (ed.), A Handbook of Phonological Theory, 307-317. Malden, MA: Blackwell.

Pickett, E. R., Blumstein, S. E. \& Burton, M. W. (1999). Effects of speaking rate on the singleton/geminate consonant contrast in Italian. Phonetica 56, 135-157.

REID, L. A. (1963). Phonology of Central Bontoc. Journal of the Polynesian Society 72, 21-26.

REID, L. A. (1973). Diachronic typology of Philippine vowel systems, Current Trends in Linguistics vol. 11: Diachronic, Areal and Typological Systems, 485-506. The Hague: Mouton.

ReID, L. A. (1976). Bontok-English Dictionary, with English Bontok Finder List. Canberra: Pacific Linguistics $\mathrm{C}-36$.

REID, L. A. (2005). A cross-generational view of contact-related phenomena in a Philippine language: Phonology. In Quakenbush, J. S. \& Dayag, D. T. (eds.), Sociolinguistics and Language Education in the Philippines and Beyond: Festschrift in Honor of Ma. Lourdes S. Bautista. Manila: Linguistic Society of the Philippines and the Summer Institute of Linguistics.

Richardson, U. (1998). Familial Dyslexia and Sound Duration in the Quantity Distinctions of Finnish Infants and Adults. Ph.D. dissertation. University of Jyväskylä, Jyväskylä, Finland.

SAto, Y. (1998). The Phonetic Reality of the Mora in Japanese. Ph.D. dissertation. University of Hawai‘ ${ }^{\circ}$ at Mānoa, Honolulu, HI.

SCHEIN, B. \& STERIADE, D. (1986). On geminates. Linguistic Inquiry 17, 697-744.

Sulkala, H. \& KaRJALAINEN, M. (1992). Finnish. London: Routledge.

THURGOOD, E. (1997). Bontok reduplication and prosodic templates. Oceanic Linguistics 36, 135-148.

THURGOOD, E. (2001). The phonetic realization of phonologically geminate affricates in Polish: the long and the short of it. Speech and Language Technology 5, 9-19.

THURGOOD, G. (1993). Geminates: a cross-linguistic examination. In Nevis, J. A., McMenamin, G. \& Thurgood, G. (eds.), Papers in Honor of Frederick H. Brengelman on the Occasion of the TwentyFifth Anniversary of the Department of Linguistics CSU Fresno, 129-139. Fresno, CA: Department of Linguistics, California State University Fresno.

VANCE, T. (1987). An Introduction to Japanese Phonology. New York: State University of New York Press. 